\title{
Olfactory orientation of the seven-spot ladybird beetle, Coccinella septempunctata (Coleoptera: Coccinellidae): Attraction of adults to plants and conspecific females
}

\author{
Mara SCHALLER and WolfGang NENTWIG* \\ Zoological Institute, University Berne, Baltzerstrasse 3, 3012 Berne, Switzerland
}

\begin{abstract}
Key words. Coccinellidae, Coccinella septempunctata, olfaction, attractant, orientation, plant-predator interaction, olfactometer, Berberis vulgaris, Tripleurospermum inodoratum
\end{abstract}

\begin{abstract}
The olfactory orientation of the aphidophagous ladybird Coccinella septempunctata L. was assessed in a Y-tube olfactometer and a choice arena. The response of the predator to 22 plants, aphid prey and conspecifics was tested. The ladybird was attracted to the odour of chopped Berberis vulgaris L. leaves, and of Tripleurospermum inodoratum (L.) Sch.-Bip. flowerheads, and males were attracted to females. Methanol extracts of $B$. vulgaris leaves were also attractive.
\end{abstract}

\section{INTRODUCTION}

Plants synthesise protective (non-volatile and volatile) chemicals when damaged by herbivores (inductive products) and even in the absence of attack by phytophages (constitutive products) (Rhoades, 1985). Constitutive chemicals may attract or "recruit" and "sustain" natural enemies before plants are attacked by herbivores (Dicke $\&$ Sabelis, 1988a, b). There are a few reports of predators using volatiles from uninfested plants to locate herbivorehabitats (e.g. Vinson, 1981; Hagen, 1986; Nordlund et al., 1988; Takabayashi et al., 1990).

Coccinella septempunctata (L.) is a widely distributed predator of several aphid species in diverse habitats in Eurasia (Hodek, 1973; Honěk, 1985). Pollen and nectar are used as alternative food sources by coccinellids when aphids are scarce (Hagen, 1962; Hodek, 1967, 1970) but there are still gaps in our understanding of their foraging behaviour, which has recently been reviewed by Ferran \& Dixon (1993). These authors conclude that an understanding of the beetles' foraging behaviour is essential for a better understanding of their effectiveness, and they suggest that the sensory abilities of these predators should be studied. In biological control programmes, the sensory relationship of predators to plants and prey are rarely considered. However, better methods of conditioning, attracting and settling predator populations may result from a better understanding of their olfactory ability (Lambin et al., 1996). To date, virtually nothing is known about habitat location by aphidophagous predators and, more specifically, whether they use plant cues to locate their prey (Lorenzetti et al., 1997).

In a recent field survey of the abundance of coccinellids on herbaceous plants only $60 \%$ of the coccinellids were found on aphid-infested plants, and the rest on plants without aphids (Schmid, 1992). The author suggests that a preference for pollen or nectar of certain plant species may account for the beetles visiting uninfested plants. Moreover, he assumed that certain plant compounds are attractive to ladybirds as shown in previous studies. Boldyrev et al. (1969) demonstrated that females of four coccinellid species were attracted to Juniperus virginiana (L.) for oviposition, apparently by olfactory stimuli. Strawberry flavour presented in a jelly is attractive to ovipositing C. septempunctata (Shands et al., 1970). C. septempunctata and Adalia bipunctata (L.) females prefer Berberis vulgaris (L.) to four other shrubs for oviposition (Shah, 1983) and the author ascribes this attraction to chemicals produced by $B$. vulgaris. In none of these experiments, however, has it been proved that coccinellids are attracted to plant volatiles by olfactory means. Therefore, in this study we used a Y-tube olfactometer and olfactory choice arena to determine the response of adult $C$. septempunctata to plant volatiles and prey and mate cues.

\section{MATERIAL AND METHODS}

\section{Experimental insects}

Most of the C. septempunctata adults used in the experiment were collected near Berne and Sierre (Switzerland) in June and July 1998. A small number was obtained from a laboratory colony (Peter Katz, Germany). Male and female beetles were kept separately in plastic boxes $(170 \times 125 \times 60 \mathrm{~mm})$ and maintained on the pea aphid, Acyrthosiphon pisum (Harris), at $20^{\circ} \mathrm{C}$ and a 18L : 6D photoperiod. To standardize the coccinellids, they were kept under these conditions for at least 2 weeks prior to being used in the experiments. Aphids were reared on potted broad bean plants, Vicia faba L. under the same light and temperature conditions as the beetles. Ladybirds were deprived of food for $24 \mathrm{~h}$ before each experiment. All experiments were conducted at $21 \pm 2^{\circ} \mathrm{C}$ and males and females were tested separately.

\section{Odour stimuli}

We tested leaves (1), blooms (b), fruits (f), and extracts of leaves (el) or extracts of blooms (eb) from the following plants (nomenclature according to Binz \& Heitz (1990): Juniperus communis L. (Cupressaceae, 1), Berberis vulgaris L. (Berberi-

\footnotetext{
* Author for correspondence; e-mail: wolfgang.nentwig@zos.unibe.ch.
} 
daceae, 1, el), Urtica dioica L. (Urticaceae, 1), Fragaria vesca L. (Rosaceae, f), Medicago sativa L. (1, b), Glycine max (L.) Merrill (both Fabaceae, 1), Oenothera biennis L. (Onagraceae, l), Heracleum mantegazzianum Sommier et Levier $(1, b)$, Daucus carota L. (both Apiaceae, 1, b), Sinapis alba L. (Brassicaceae, 1), Silene alba (Miller) E.M.L. Krause (1), Agrostemma githago L. (Caryophyllaceae, 1), Chenopodium album L. (Chenopodiaceae, 1, b), Knautia arvensis (L.) Coulter (Dipsacaceae, 1), Symphytum officinale L. (Boraginaceae, 1), Verbascum densiflorum Bertol. (Scrophulariaceae, 1), Achillea millefolium L. (L), Tripleurospermum inodoratum (Mérat) Wagenitz (l, b, eb), Tanacetum vulgare L. (1, b), Artemisia vulgaris L. (1), Cirsium arvense (L.) Scop. $(1, b)$, and Centaurea cyanus L. (all Asteraceae, $1, b)$. The test material of each species was obtained from at least 5 individuals from locations near Berne or Sierre. Only fresh plants uninfested by aphids were used. In addition, the response of the predator to the odour of $A$. pisum and their honeydew was determined. The aphids were taken from a laboratory colony reared on Vicia faba, and both larvae and adults were used.

\section{Plant extracts}

Plant parts, which proved to be highly attractive to coccinellids in choice experiments, were extracted. A methanol and an ether extract were produced using an extraction appliance "fexIKA 200 control" (IKA-Maschinenbau - Janke \& Kunkel GmbH \& Co., Staufen, Germany). For each extract a volume of about $100 \mathrm{~cm}^{3}$ of plant material (B. vulgaris leaves: $12.5 \mathrm{~g}, T$. inodoratum flowerheads: $5.7 \mathrm{~g}$ ) and $80 \mathrm{ml}$ of the solvent, either methanol (purity 99\%) or tert-Butyl methyl ether (purity 99.8\%) were used. Each extract was the product of two extraction cycles, each lasting twenty minutes, at temperatures of 140 and $130^{\circ} \mathrm{C}$ for the methanol and ether extracts, respectively, and cooled at $50^{\circ} \mathrm{C}$. Extracts were used for experiments immediately after cooling.

\section{Olfactometer - apparatus and experimental procedure}

Our Y-tube olfactometer (Fig. 1) consisted of twelve glass Ytubes arranged in two sets of six vertically stacked tubes, four glass distributor tubes that connected the odour chambers with the Y-tube, two glass odour chambers containing water that guaranteed a uniform humidity, and a ventilator. Visual biases were excluded by the arrangement of the distributor tubes (see Fig. 1). The ventilator generated an airflow through activated charcoal of $0.44 \pm 0.01 \mathrm{~m} / \mathrm{s}$ (measured with an anemometer ThermoAir2, Schiltknecht, Switzerland). Light came from opposite the entrance and helped to induce the beetles to walk upwind towards the odour source. Glassware was washed in detergent solution, rinsed with distilled water and heated for $1 \mathrm{~h}$ at $100^{\circ} \mathrm{C}$ after every five tests. Additionally, the Y-tubes were cleaned with ethanol after each test.

We used $8 \mathrm{~g}$ of leaves, flowers or fruits when the beetles were offered a choice between clean humidified air and an odour stimulus. Blooms and fruits were left intact while leaves were chopped to release a larger amount of volatiles. Honeydew was presented on $8 \mathrm{~g}$ of intact broad bean leaves and we tested $2 \mathrm{~g}$ aphids or 10 adult $C$. septempunctata. When using methanol and ether extracts, cotton balls soaked with a $2 \mathrm{ml}$ extract served as the odour source, and $2 \mathrm{ml}$ of the solvent served as the control. They were dried until the solvent visually seemed to have evaporated. If a beetle did not reach the centre of the Y-tube within $10 \mathrm{~min}$, it was counted as "no-choice". In the centre of the Y-tube a beetle was allowed $5 \mathrm{~min}$ to choose one of the olfactometer arms (number of replicates at least 15 male and 15 female beetles, the results were statistically analysed using chisquare tests).

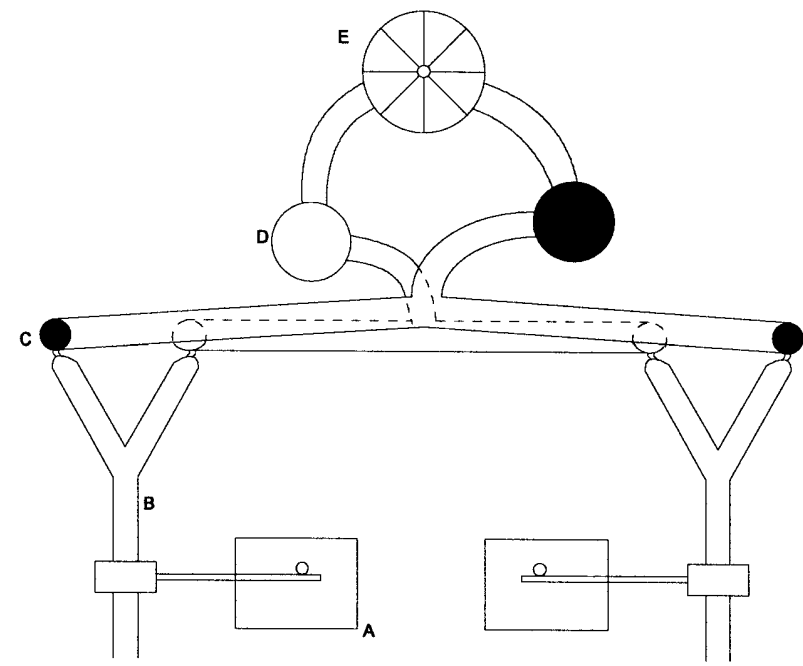

Fig. 1. Diagram of the glass olfactometer apparatus. A - tripod to which the tubes were attached by means of clamps and sleeves; B - Y-tube made from $23 \mathrm{~mm}$ internal diameter glass tubing with a $270 \mathrm{~mm}$ long basal stem and two arms $220 \mathrm{~mm}$ long, which diverge from each other at an angle of $60^{\circ} ; \mathrm{C}-$ glass distributor tubes; D - odour chamber with $350 \mathrm{ml}$ distilled water and an aluminium stand for the odour source; E - ventilator, which blew air through activated charcoal.

\section{Olfactory choice arena}

A simple acrylic glass box ("olfactory choice arena") $(18 \mathrm{~cm}$ long $\times 13 \mathrm{~cm}$ wide $\times 6 \mathrm{~cm}$ high, with rectangular corners) was used to screen the attractiveness of chemical stimuli for C. septempunctata. This box was covered by an acrylic lid. In two opposite corners the test and control substances were deposited. In a first set of experiments, the predator's response to volatile chemicals emanating from host plants, honeydew, aphids or mates was studied. For plant odour stimuli $0.8 \mathrm{~g}$ chopped leaves or $0.8 \mathrm{~g}$ intact blooms or fruits were used. Honeydew was presented on $0.8 \mathrm{~g}$ of intact broad bean leaves. In the case of the other non-plant stimuli, $0.8 \mathrm{~g}$ aphids or four adult female C. septempunctata were used. Odour sources were wrapped in cotton gauze $\left(14 \times 14\right.$ meshes $\left./ \mathrm{cm}^{2}\right)$. As a control the same amount of test material was wrapped in transparent plastic film ("Saran") to avoid odours being emitted, before also being wrapped in cotton mesh in the same manner as the odour source. In a preliminary experiment, the effect of the plastic film was tested, by placing it in one of two otherwise empty gauze bags. Using the same bioassay, the response of adult predators to methanol and ether extracts of plant material was observed. Round filter papers (diameter $2 \mathrm{~cm}$ ) soaked in $1 \mathrm{ml}$ plant extract served as an odour source, while filter papers soaked in $1 \mathrm{ml}$ pure solvent served as the control. They were dried until the solvent visually seemed to have evaporated and then were placed in two opposite corners of the arena, which was then placed on a black background. Six and seven replicates were performed with fresh odour stimuli and plant extracts, respectively. After each replicate, the arena was rinsed with ethanol and rotated by $180^{\circ}$ to compensate for directional or chamber biases. Five adult C. septempunctata males or females per replicate were released from a petri dish lid (diameter $5.5 \mathrm{~cm}$ ), placed in the middle of the arena and then the arena was covered with the lid. Times taken for the first beetle to contact the odour source and the control were recorded and were compared using the Wilcoxon signed ranks test $(\alpha=0.05)$. 


\section{RESULTS}

\section{Olfactometer}

Male and female $C$. septempunctata did not show a preference for one arm of the olfactometer when clean humid air was passed through both arms $\left(\chi^{2}=0.13\right.$, df $=$ $1, \mathrm{n}=30, \mathrm{P}>0.7$ for males and females). Neither male nor female $C$. septempunctata showed a preferrence for the odours from 22 plant species: (J. communis (1), B. vulgaris, $(1, \mathrm{ml}, \mathrm{el}), U$. dioica $(\mathrm{l}), F$. vesca $(\mathrm{f}), M$. sativa $(1$, b), G. max (1), O. biennis (1), H. mantegazzianum $(1, \mathrm{~b})$, D. carota (1, b), Sinapis alba (1), Silene alba (1), A. githago (1), C. album (1, b), $K$. arvensis (1), S. officinale (1), V. densiflorum (1), A. millefolium (1), T. inodoratum (1, b, mb, eb), T. vulgare (1, b), A. vulgaris (1), C. arvense (1, b), C. cyanus $(1, b)(1=$ leaves, $b=$ blossoms, $f=$ fruits, $m$ $=$ methanol extract, $\mathrm{e}=$ ether extracts). They also did not respond to either honeydew or aphid odour.

\section{Olfactory choice arena}

Male and female C. septempunctata did not differentiate between the packing for the odour source and the packing for the control in the preliminary experiment (Wilcoxon signed ranks test, $\mathrm{n}=12, \mathrm{P}>0.9$ for males; $\mathrm{P}$ $>0.6$ for females). Volatiles from $B$. vulgaris and T. inodoratum were attractive to the ladybirds, while those from the other 20 plant species mentioned above were not (Table 1). B. vulgaris leaves elicited orientation in female ladybirds which found this odour source significantly quicker than the control ( $\mathrm{P}=0.046)$. The methanol extract of $B$. vulgaris leaves was strongly attractive for females $(P=0.018)$. Male beetles did not respond to leaves, but were slightly attracted by the methanol extract of the leaves; the effect was nearly significant $(P=0.063)$. Ether extracts were not attractive to either male or female $C$. septempunctata. Odours from $T$. inodoratum flowerheads were attractive to male $C$. septempunctata $(P=0.0028)$, but not to females. However, methanol soluble fractions of $T$. inodoratum flowerheads repelled both, males and females ( $\mathrm{P}=0.018$ for males; $\mathrm{P}=0.023$ for females). On the other hand, ether soluble fractions of $T$. inodoratum flowerheads were neither attractive or repellent for males and females. $T$. inodoratum leaves repelled C. septempunctata males, and the effect was nearly significant. $C$. arvense leaves repelled females $(\mathrm{P}=0.046)$, but neither attracted or repelled the males. Odours from C. septempunctata females attracted C. septempunctata males. Males found females significantly quicker than the control $(P=0.046)$. No other odour source elicited orientation in C. septempunctata.

\section{DISCUSSION}

\section{Response to plants}

Only the volatiles of a few plants were attractive to $C$. septempunctata, while most of the 22 plants were neutral in terms of olfactory attraction and some even repelled the ladybird. Attractive volatiles are produced by $B$. vulgaris leaves. Coccinellids were also attracted to methanol extracts of $B$. vulgaris leaves. Since ether extracts were not attractive, it seems likely that the attractant is a polar substance or a mixture of polar substances. Females responded more strongly to methanol extracts than males, whose response was not significant. A volatile from $T$. inodoratum flowerheads was attractive for adult males of C. septempunctata. However, it was not possible to extract the volatile; methanol extracts of $T$. inodoratum flowerheads repelled and ether extracts were neutral in their attractiveness to the ladybird. In addition, the attractive volatile does not seem to be present in $T$. inodoratum leaves as the odour from them repelled the ladybird. This is the first report of C. septempunctata being olfactorily attracted by plant compounds.

It is known that plant substances can induce oviposition in coccinellids (Boldyrev et al., 1969; Shands et al., 1970). For example, B. vulgaris stimulates oviposition in coccinellids (Shah, 1983). The leaves of B. vulgaris are a preferred oviposition substrate for C. septempunctata and A. bipunctata and water extracts of the leaves induced oviposition in both species of coccinellids. Shah (1983) suggested that a substance specific to $B$. vulgaris may act as a chemical stimulus. It is possible that the plant stimu-

TABLE 1. Times taken for the first $C$. septempunctata (male or female) to make contact with an odour source and the control, mean \pm s.d., $n=6$ and 7 for fresh odour source and plant extracts, respectively. The significance of the differences was tested by the non-parametric Wilcoxon signed ranks test and asterisked $\mathrm{P}$-values are significant $(\mathrm{P}<0.05)$.

\begin{tabular}{|c|c|c|c|c|c|c|c|}
\hline \multirow{2}{*}{ Odour stimulus $^{1}$} & & \multicolumn{2}{|c|}{ Time (sec) for males } & \multirow{2}{*}{$\mathrm{P}$} & \multicolumn{2}{|c|}{ Time (sec) for females } & \multirow{2}{*}{$\mathrm{P}$} \\
\hline & & to odour & to control & & to odour & to control & \\
\hline \multirow[t]{3}{*}{ B. vulgaris } & leaves & $344 \pm 307$ & $496 \pm 326$ & 0.463 & $390 \pm 190$ & $752 \pm 230$ & $0.046^{*}$ \\
\hline & met. ex., leaves & $355 \pm 287$ & $682 \pm 232$ & 0.063 & $197 \pm 252$ & $621 \pm 303$ & $0.018^{*}$ \\
\hline & eth. ex., leaves & $529 \pm 362$ & $620 \pm 283$ & 0.866 & $579 \pm 335$ & $550 \pm 367$ & 0.866 \\
\hline \multirow[t]{4}{*}{ T. perforatum } & leaves & $547 \pm 277$ & $256 \pm 167$ & 0.075 & $325 \pm 311$ & $290 \pm 204$ & 0.917 \\
\hline & flowers & $76 \pm 60$ & $358 \pm 380$ & $0.028 *$ & $588 \pm 263$ & $416 \pm 240$ & 0.600 \\
\hline & met. ex., flowers & $700 \pm 261$ & $372 \pm 219$ & $0.018^{*}$ & $619 \pm 368$ & $251 \pm 253$ & $0.028^{*}$ \\
\hline & eth. ex., flowers & $430 \pm 384$ & $580 \pm 351$ & 0.499 & $326 \pm 360$ & $331 \pm 366$ & 0.310 \\
\hline \multirow[t]{2}{*}{ C. arvense } & leaves & $462 \pm 384$ & $489 \pm 397$ & 0.917 & $749 \pm 193$ & $289 \pm 127$ & $0.046^{*}$ \\
\hline & flowers & $334 \pm 339$ & $377 \pm 313$ & 0.917 & $599 \pm 370$ & $364 \pm 334$ & 0.643 \\
\hline C. septempunctata & females & $216 \pm 337$ & $555 \pm 246$ & $0.046^{*}$ & & & \\
\hline
\end{tabular}

${ }^{1}$ met. ex. = methanol extracts; eth. ex. = ether extracts. 
lus that induces oviposition in coccinellids is also responsible for the plants' attractiveness, although the experiments of Shah did not discriminate between perception via olfaction or gustation.

In his field study Schmid (1992) searched weed species visually for coccinellids. He found most coccinellids on plants infested with aphids, but on several plants coccinellids ate pollen although aphids were present. The author concluded that pollen is an important alternative food since $40 \%$ of all coccinellids were found on plants without aphids. On some of these plants the author recorded coccinellids feeding on pollen while on others the reason for the beetles' presence was not obvious. He concluded that secondary plant compounds may attract ladybirds to such plants. Among the weeds, which Schmid (1992) recorded as frequently visited by C. septempunctata, was $T$. inodoratum; the only plant that we could confirm as attracting ladybirds by means of its odour. $T$. inodoratum was one of the plants on which Schmid (1992) found C. septempunctata reproducing and feeding on pollen even though aphids were present.

Why should a plant be attractive to coccinellids? "Constitutive products" are protective (volatile or non-volatile) chemicals that plants produce in the absence of attack by phytophages (Rhoades, 1985). These chemicals may have the potential to attract or "recruit" and "sustain" natural enemies before plants are invaded by herbivores (Dicke \& Sabelis, 1988a, b). A predator's response to such an attractant is only evolutionary stable if the predator gains an advantage from visiting the plant. Such an interaction would be an example of a mutualism between plants and their herbivores' enemies, an interaction whose existance is predicted by Price et al. (1980). Flowers provide a reservoir of resources such as nutrients, mating sites, alternate hosts and shelter, which improves the establishment and performance of many anthophilous predators (Altieri \& Whitcomb, 1979; Altieri \& Letourneau, 1982; Andow 1983; van Emden, 1989; Jervis \& Kidd, 1996).

The ecological significance of the attractiveness response of $B$. vulgaris and $T$. inodoratum to $C$. septempunctata is unclear. It is possible that the presence of pollen is the reason why C. septempunctata, once attracted, stays on these plants even in the absence of aphids. Pollen from different plants have different chemical compositions and therefore are not equal in terms of food quality for coccinellids (Smith, 1960, 1961). Thus, a preference for certain plants is likely to develop. The attractive chemicals may also mimic chemicals that are important in ladybird ecology. It is possible that ladybirds mistake the attractants in B. vulgaris and T. inodoratum for the odour of certain aphids, pollen or nectar, or for the ladybird's sex pheromone or aggregation pheromone. However, there are no other reports of $C$. septempunctata, being attracted by plant substances.

\section{Response to prey cues}

According to Hodek \& Honěk (1996), the question of whether coccinellids can find their prey by visual and olfactory cues, has not yet been resolved. C. septempunctata septempunctata and C. septempunctata brucki orientate towards aphid prey from a distance of about 7 $\mathrm{mm}$ under light and are unable to locate prey in the dark (Nakamuta, 1984; Nakamuta \& Saito, 1985). These results suggest that adult coccinellids, when close to prey, may perceive them by visual means. On the other hand, Sengonca \& Liu (1994) found evidence for olfactory orientation in C. septempunctata towards Myzus persicae (Sulzer) and Aphis fabae (Scopoli). They demonstrated that, in an 8-arm olfactometer similar to the olfactory choice arena used here, adult $C$. septempunctata preferred aphid odours to those from non-prey insect. We were unable to confirm this in our study. Coccinellids neither oriented towards odour of $A$. pisum or towards honeydew presented on broad bean leaves (see Carter \& Dixon, 1984). However, coccinellids showed different preferences for different aphid species (Sengonca \& Liu, 1994) and $A$. pisum was among the less preferred of the aphids tested.

\section{Response to beetles}

C. septempunctata males were attracted by the odour of conspecific females. This is contrary to what was earlier (see Sengonca \& Liu, 1994 below) assumed about this ladybird's sexual behaviour. Majerus (1994) stated that $C$. septempunctata, unlike many other insect species, do not show any long-distance attraction between the sexes, and that one sex does not attract the other by means of airborne pheromones or sound. According to him, mating partners seem to find each other more or less by chance. In $A$. bipunctata males appear to mainly search for females (Hemptinne et al., 1998). We have not examined whether females are attracted by males, therefore it cannot be determined if the attractant stimulus is a sex specific cue. Such a cue may be useful in group formation by coccinellids at overwintering sites and its existence is hypothesised by Majerus (1994). That is, ladybirds may produce both mating and aggregative pheromones. Sengonca \& Liu (1994) also found that C. septempunctata adults were attracted by the odour of conspecifics, but they did not differentiate between males and females. Our own findings support those of Sengonca \& Liu, in that the odour of $C$. septempunctata adults can be detected by conspecifics. Further investigations are needed to assess whether the attractant stimulus is species or sex specific.

In conclusion, we have shown that $C$. septempunctata may orientate to plant odours. Studies have shown that plant compounds affect this beetle's oviposition behaviour (Boldyrev et al., 1969; Shah, 1983). However, this is the first demonstration that C. septempunctata can orient to plant volatiles. The fact that these aphidophagous beetles show olfactory orientation towards constitutive plant compounds gives a new insight into the foraging behaviour of these predators. The demonstration that plant products may act as modulators between the first and third trophic levels has implications for biological control programmes, e.g. the enhancing of the local abundance of coccinellids by using plant compounds as attractants. 
ACKNOWLEDGEMENTS. We are grateful to S. Bacher, A. Honěk and one anonymous referee for helpful comments on the manuscript. Thanks are expressed also to M. Waldburger from FAL Zurich-Reckenholz for supplying an aphid population and to J. Friedli, T. Turlings and E. Jutzi for further support.

\section{REFERENCES}

Altieri M.A. \& Letourneau D.K. 1982: Vegetation management and biological control in agroecosystems. Crop Prot. 1: 405-430.

AltiERi M.A. \& WhitcomB W.H. 1979: The potential use of weeds in manipulation of beneficial insects. Hort. Sci. 14: $12-18$.

ANDow D.A. 1983: Effect of agricultural diversity on insect populations. In Lockeretz W. (ed.): Environmentally Sound Agriculture. Praeger, New York, pp. 91-115.

Boldyrev M.I., Wilde W.H.A. \& SMith B.C. 1969: Predaceous coccinellid oviposition responses to Juniperus wood. Can. Entomol. 101: 1199-1206.

Binz A. \& Heitz C. 1990: Schul- und Exkursionsflora für die Schweiz. Schwabe, Basel, 659 pp.

CARTER M.C. \& Duxon A.F.G. 1984: Honeydew: an arrestant stimulus for coccinellids. Ecol. Entomol. 9: 383-387.

Dicke M. \& SABELIS M.W. 1988a: Infochemical terminology: should it be based on cost-benefit analysis rather than origin of compounds? Funct. Ecol. 2: 131-139.

Dicke M. \& SABELIS M.W. 1988b: How plants obtain predatory mites as bodyguards. Neth. J. Zool. 38: 148-165.

EMDEN H.F. VAN 1989: Plant diversity and natural enemy efficiency in agroecosystems. In Mackauer M., Ehler L.E. \& Roland J. (eds): Critical Issues in Biological Control. Intercept, Andover, pp. 63-80.

FERran A. \& Dixon A.F.G. 1993: Foraging behaviour of ladybird larvae (Coleoptera: Coccinellidae). Eur. J. Entomol. 90: $383-402$.

HAGEN K.S. 1962: Biology and ecology of predaceous Coccinellidae. Annu. Rev. Entomol. 7: 289-326.

HAGEN K.S. 1986: Ecosystem analysis: Plant cultivars (HPR), entomophagous species and food supplements. In Boethel D.J. \& Eikenbary R.D. (eds): Interactions of Plant Resistance and Parasitoids and Predators of Insects. Ellis Horwood, Chichester, pp. 151-197.

Hemptinne J.-L., Lognay G. \& Dixon A.F.G. 1998: Mate recognition in the two-spot ladybird beetle, Adalia bipunctata: role of chemical and behavioural cues. J. Insect Physiol. 44: 1163-1171.

HoDEK I. 1967: Bionomics and ecology of predaceous Coccinellidae. Annu. Rev. Entomol. 12: 79-104.

HoDEK I. 1970: Coccinellids and modern pest management. Bioscience 20: 543-552.

Hodek I. 1973: Biology of Coccinellidae. Academia, Prague \& Dr W. Junk, The Hague, 260 pp.

Hodek I. \& HonĚK A. 1996: Ecology of Coccinellidae. Kluwer Academic Publishers, Dordrecht, $464 \mathrm{pp}$.

HoNĚK A. 1985: Habitat preferences of aphidophagous coccinellids (Coleoptera). Entomophaga 30: 253-264.
Jervis M.A. \& KIDD N.A.C. 1996: Insect Natural Enemies. Chapman \& Hall, London, $491 \mathrm{pp}$.

Lambin M., Ferran A. \& Maugan K. 1996: La prise d'information visuelles chez la coccinelle Harmonia axyridis. Entomol. Exp. Appl. 79: 121-130.

Lorenzetti F., Arnason J.T., Philogène B.J.R. \& Hamilton R.I. 1997: Evidence for spatial niche partitioning in predaceous aphidophaga: use of plant colour as a cue. Entomophaga $\mathbf{4 2}$ $49-56$.

MAJeRus M.E.N. 1994: Ladybirds. The New Naturalist Series, Harper Collins Publishers, London, 367 pp.

NAKAMUTA K. 1984: Visual orientation of a ladybeetle, Coccinella septempunctata L. (Coleoptera: Coccinellidae), towards its prey. Appl. Entomol. Zool. 19: 82-86.

NAKAMUTA K. \& SAITO T. 1985: Recognition of aphid prey by the lady beetle, Coccinella septempunctata brucki Mulsant (Coleoptera, Coccinellidae). Appl. Entomol. Zool. 20: 479-483.

NordLund D.A., Lewis W.J. \& Altieri M.A. 1988: Influences of plant-produced allelochemicals on the host/prey selection behavior of entomophagous insects. In Barbosa P. \& Letourneau D. (eds): Novel Aspects of Insect-Plant Interactions. Wiley and Sons, New York, pp. 65-90.

Price P.W., Bouton C.E., Gross P., McPheron B.A., Thompson J.N. \& WeIs A.E. 1980: Interactions among three trophic levels: Influence of plants on interactions between insect herbivores and natural enemies. Annu. Rev. Ecol. Syst. 11: 41-65.

RHOADES D.F. 1985: Offensive-defensive interactions between herbivores and plants: their relevance in herbivore population dynamics and ecological theory. Amer. Nat. 125: 205-238.

Scrmm A. 1992: Untersuchungen zur Attraktivität von Ackerwildkräutern für aphidophage Marienkäfer (Coleoptera, Coccinellidae). Agrarökologie 5: 1-122.

SEngonca C. \& Liu B. 1994: Responses of the different instar predator, Coccinella septempunctata L. (Coleoptera: Coccinellidae), to the kairomones produced by the prey and nonprey insects as well as the predator itself. Z. PflKrankh. PflSchutz. 101: 173-177.

Shands W.A., Holmes R.L. \& Simpson G.W. 1970: Improved laboratory production of eggs of Coccinella septempunctata. J. Econ. Entomol. 63: 315-317.

SHAH M.A. 1983: A stimulant in Berberis vulgaris inducing oviposition in coccinellids. Entomol. Exp. Appl. 33: 119-120.

SMITH B.C. 1960: A technique for rearing coccinellid beetles on dry foods, and influence of various pollens on the development of Coleomegilla maculata lengi Timb. (Coleoptera: Coccinellidae). Can. J. Zool. 38: 1047-1049.

SMITH B.C. 1961: Results of rearing some coccinellid (Coleoptera: Coccinellidae) larvae on various pollens. Proc. Entomol. Soc. Ont. 91: 270-271.

TaKabayashi J., Dicke M., KemerinK J. \& Veldhuizen T. 1990: Environmental effects on production of a plant synomone that attracts predatory mites. Symp. Biol. Hung. 39: 541-542.

VINSON S.B. 1981: Habitat location. In Nordlund D.A., Jones R.L. \& Lewis W.J. (eds): Semiochemicals: Their Role in Pest Control. Wiley, New York, pp. 51-77.

Received May 3, 1999; accepted November 11, 1999 